\title{
Peripheral arthritis in the elderly: a hospital study
}

\author{
MICHAEL L JENKINSON, ${ }^{1}$ MARY R BLISS, ${ }^{1}$ ANTHONY T BRAIN, ${ }^{1}$ AND \\ DAVID L SCOTT ${ }^{2}$
}

From the ${ }^{1}$ Department of Geriatric Medicine, Hackney Hospital, London; and the ${ }^{2}$ Department of Rheumatology, St Bartholomew's Hospital, London

SUMmary One hundred consecutive patients admitted to an acute geriatric unit were examined for evidence of peripheral arthritis with recognised criteria used to define osteoarthritis, rheumatoid arthritis, pyrophosphate arthropathy, gout, and disorders of the shoulder joint. The presence of arthritis and its severity were related both to functional independence and to a recognition by the patient that joint problems were impairing independence. Seventy six patients had clinical peripheral arthritis; 48 had arthritis contributing to loss of function, and 19 of these did not volunteer evidence of their joint disease. The common occurrence of arthritic conditions in the elderly, with consequential disability and dependency, suggests that increased medical awareness may be required to prevent unnecessary morbidity. Our findings need confirmation in community based studies.

Key words: geriatric, osteoarthritis, rheumatoid arthritis, chondrocalcinosis, gout, disability.

There is substantial evidence that owing to the aging population in Western countries the duration of terminal dependency in the elderly population is increasing. Epidemiological evidence from the United Kingdom, ${ }^{1}$ New Zealand, ${ }^{2}$ and Canada ${ }^{3}$ suggests that up to $80 \%$ of the gain in life expectancy since the 1950s consists of years of increased disability. For this reason as life expectancy continues to increase high priority will have to be given to reduction of disability and dependency in advanced old age.

It has been well documented that the commonest cause of disability in those over 75 is arthritis or rheumatism. ${ }^{4}$ The commonest cause of terminal dependency due to loss of mobility, confinement in bed or in the house is also arthritis or rheumatism. ${ }^{5}$ The interaction of several diseases causing increased disability and dependency is also important. It has been noted that management and outcome of rheumatological disorders are increasingly affected by other processes after retirement. ${ }^{6}$ Assessment of disability, even in individuals, is rarely consistent between clinicians because of the many factors involved. The apportioning between several dis-

Accepted for publication 6 July 1988.

Correspondence to Dr Michael L Jenkinson, Department of Geriatric Medicine, Hackney Hospital, Homerton High St, London E9 6BE, UK. eases of objective measurements of functional disability is difficult but is a key to better management.

Recent work suggests an under-reporting by elderly patients of shoulder disorders. ${ }^{7}$ We have investigated the possibility that there is a widespread under-reporting of peripheral joint disorders by elderly people. We studied consecutive patients over the age of 65 admitted to acute or rehabilitation geriatric wards. Sufficient information was gathered to compare our patient population with that of other studies in the same age group, and to interpret joint disorders which affected the patient's total disabilities and dependency.

\section{Patients and methods}

One hundred and two consecutive patients, over the age of 65 years, were interviewed and examined in an acute geriatric unit during a 10 week period. They were in the convalescent phase after an emergency admission, undergoing rehabilitation, or being investigated. Two patients were excluded from the study: one had a severe terminal illness precluding interview and the other refused consent, leaving 100 patients enrolled in the study. No criteria apart from consent were applied in the enrolment of subjects. We included patients with dementia, for whom an adequate medical history might be impossible to obtain, because they are 
representative of a significant proportion of the high dependency elderly population.

The medical records were reviewed, medical history associated with or relevant to joint pathology recorded, and information relating to new, active, and past diagnoses was recorded. Information on current and previous mobility, including the use of aids, was obtained. A clinically indicated examination and investigation, including plain $x$ rays, blood tests, and synovial fluid examination, were then undertaken, enabling an accurate rheumatological diagnosis to be made according to defined criteria. These were (a) idiopathic osteoarthritis: American Rheumatism Association (ARA) criteria for the knee. ${ }^{8}$ Identical criteria were applied to other joints. (b) probable osteoarthritis: criteria of Forman et al for the $\mathrm{knee}^{9}$ or Bergström et al ${ }^{10}$ unless classified by other criteria; $(c)$ rheumatoid arthritis: 1958 ARA criteria $^{11}$; $(d)$ rotator cuff tendinitis: criteria of Cyriax $^{12}$; (e) frozen shoulder and rotator cuff rupture: criteria of Chard and Hazleman ${ }^{7} ;(f)$ chondrocalcinosis: criteria of Bergström et $a^{10} ;(g)$ crystal arthropathy: criteria of Doherty and Dieppe. $^{13}$

All subjects had a detailed joint examination of the hands, shoulders, and knees to allow comparison of this population with patients of previous epidemiological studies. A clinical assessment was made of the contribution of any joint disease to decreased mobility or function, as shown by loss of independence in one or more of the six dimensions of the Katz index of activities of daily living. ${ }^{14}$ The validated Hodkinson 10 point mental status questionnaire score ${ }^{15}$ was used with patients who were not deaf or blind and not suffering from receptive or nominal dysphasia.

\section{Results}

Seventy seven of the 100 patients had clinical peripheral joint disease. Arthritis was present in 75 of the 77 according to the criteria outlined above, and another patient had temporal artery, giant cell arteritis proved by biopsy. Periarticular Paget's disease of the bone was indicated in one case by plain $x$ ray, and this patient was not considered to have peripheral arthritis.

Fifteen patients had had an operation after fracture of the proximal femur, and five had had prosthetic hip replacements - in all cases for primary osteoarthritis (OA) of the hip. None had prosthetic knee replacements.

Table 1 presents a profile of our study population. The 25 men (mean age 78 years, range 65-90) were younger than the women (mean age 82 .years, range 65-95), their medical profile differed, and none of the men had had fractured proximal femura. The numbers of patients with new or active diagnoses in our study group (as extracted purely from current medical records) were not significantly different from those reported in a recent study from a geriatric assessment and rehabilitation unit (Table 2). ${ }^{16}$ Thirty two patients had peripheral arthritis

Table 1 Demographic and clinical features of the patient population

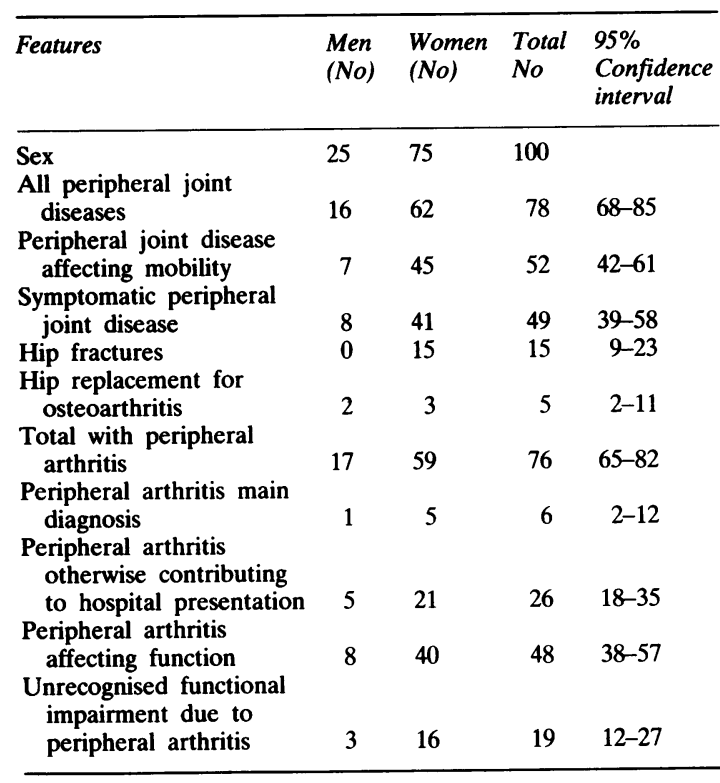

Table 2 Number of patients with new or active diagnoses on admission

\begin{tabular}{lll}
\hline Diagnosis & $\begin{array}{l}\text { This study } \\
(n=100)\end{array}$ & $\begin{array}{l}\text { Previous study } \\
(n=205)\end{array}$ \\
\hline Neuropsychiatric disorders & 41 & 62 \\
Arthritis & 23 & 30 \\
Stroke & 22 & 29 \\
Trauma & 16 & 23 \\
Cardiac disease & 13 & 42 \\
Faecal impaction & 11 & 15 \\
Urinary disease & 10 & 24 \\
Malignant neoplasm & 10 & 13 \\
Pneumonia & 8 & 19 \\
Chronic obstructive airways & & \\
$\quad$ disease & 8 & 16 \\
Adverse drug reactions & 7 & 24 \\
Parkinson's disease & 4 & 18 \\
Orthostatic hypotension & 4 & 13 \\
Anaemia & 2 & 11 \\
\hline
\end{tabular}

There was no significant difference by $\chi^{2}$ test. 
requiring treatment, though the medical record had indicated this in only 26 .

Disease in the axial skeleton was not studied in this survey, apart from information necessary to exclude axial skeleton abnormality potentially related to peripheral arthritis. Seven patients did, however, have diseases of the axial skeleton, mainly cervical spondylosis or recent vertebral collapse, which was an active problem on hospital presentation, and another 20 had a past history of symptoms of the disease.

Table 1 shows the number of patients with peripheral joint disease, the number recognising the presence of this disease, and the number whose joint disease affected function according to the Katz criteria. Nineteen patients assessed to have peripheral arthritis clinically affecting function did not recognise this fact themselves. Loss of mobility was primarily due to peripheral arthritis (four men, 27 women), fractured hip (seven women) and other causes (17 men, 26 women).

Table 3 summarises the peripheral joint diseases and joint involvement present in quintile cohorts. Five patients had rheumatoid arthritis (either definite or classical by ARA criteria), four had clinical joint disease associated with pyrophosphate arthropathy (all idiopathic), three had gout associated with diuretic treatment, one woman had giant cell arteritis, and one had a frozen shoulder without other peripheral arthritis. No other connective tissue diseases were diagnosed. There were no statistically significant trends with age or mental status score for any type of peripheral arthritis.

Symptoms and signs suggesting OA were present in 62 patients, of whom only 35 met recognised criteria. Twelve of the remaining 27 had joint disease indicated by joint distortion or limited range of movement without pain or tenderness, but which affected function. We excluded deformity at the metacarpophalangeal joints of the hand as it is very common in this age group ${ }^{17}$ and is difficult to relate to function.

Table 4 shows the main joints affected by arthritis. Arthritis was more common in all joints with increasing age, an effect mainly due to $\mathrm{OA}$ or probable OA (Table 2).

Of the 20 patients with shoulder disease, five had rheumatoid arthritis. Thus 15 of 95 patients had symptomatic shoulder disease, a proportion which is not significantly different $\left(p\left(\chi^{2}\right)>0 \cdot 3\right)$ from the 21

Table 3 Numbers of patients with arthritis affecting peripheral joints

\begin{tabular}{|c|c|c|c|c|c|c|c|c|}
\hline Age quintile & $R A^{*}$ & $P A^{*}$ & Gout & $O A^{*}$ & $\begin{array}{l}\text { Probable } \\
\text { OA }\end{array}$ & $\begin{array}{l}\text { Other } \\
\text { arthritis }\end{array}$ & $\begin{array}{l}\text { No } \\
\text { arthritis }\end{array}$ & $\begin{array}{l}\text { Number in } \\
\text { sample }\end{array}$ \\
\hline $65-69$ & 1 & 0 & 0 & 3 & 1 & 0 & 2 & 7 \\
\hline $70-74$ & 0 & 0 & 0 & 2 & 5 & 1 & 4 & 12 \\
\hline $75-79$ & 1 & 2 & 0 & 7 & 4 & 0 & 6 & 20 \\
\hline $80-84$ & 1 & 1 & 2 & 5 & 11 & 0 & 4 & 24 \\
\hline $85-89$ & 1 & 1 & 1 & 12 & 6 & 1 & 8 & 30 \\
\hline $90+$ & 1 & 0 & 0 & 6 & 0 & 0 & 0 & 7 \\
\hline Total & 5 & 4 & 3 & 35 & 27 & 2 & 24 & 100 \\
\hline interval & $2-11$ & $1-9$ & $1-8$ & $26-44$ & $19-36$ & $0-6$ & $16-33$ & \\
\hline
\end{tabular}

${ }^{*} \mathrm{RA}=$ rheumatoid arthritis; $\mathrm{PA}=$ pyrophosphate arthropathy; $\mathrm{OA}=$ osteoarthritis.

Table 4 Peripheral joints affected by arthritis

\begin{tabular}{|c|c|c|c|c|c|c|}
\hline \multirow[t]{2}{*}{ Age quintile } & \multirow{2}{*}{$\begin{array}{l}\text { Patients with } \\
\text { arthritis } \\
(\mathrm{No})\end{array}$} & \multicolumn{5}{|c|}{ Distribution of joints affected } \\
\hline & & Hand & Shoulder & Hip & Knee & Other \\
\hline $65-69$ & 5 & 2 & 2 & 1 & 5 & 1 \\
\hline $70-74$ & 8 & 1 & 1 & 2 & 6 & 1 \\
\hline $75-79$ & 14 & 4 & 3 & 4 & 10 & 1 \\
\hline $80-84$ & 20 & 7 & 5 & 6 & 12 & 3 \\
\hline $85-89$ & 22 & 8 & 5 & 7 & 17 & 2 \\
\hline $90+$ & 7 & 3 & 3 & 2 & 4 & 1 \\
\hline Total & 76 & 25 & 19 & 22 & 54 & 9 \\
\hline
\end{tabular}


Table 5 Prevalence of shoulder disorder in two elderly populations

\begin{tabular}{lll}
\hline Diagnosis & $\begin{array}{l}\text { This study } \\
(n=100)\end{array}$ & $\begin{array}{l}\text { Previous study }^{7} \\
(n=100)\end{array}$ \\
\hline Stroke related shoulder problems & 5 & 6 \\
Rotator cuff tendinitis & 1 & 5 \\
Chronic rotator cuff rupture & 0 & 7 \\
Primary frozen shoulder & 1 & 2 \\
Glenohumeral osteoarthritis & 7 & 2 \\
Apatite related shoulder arthritis & 1 & 1 \\
No shoulder disorder & 80 & 79 \\
\hline
\end{tabular}

out of 100 cases reported by Chard and Hazleman in an acute geriatric population (Table 5). ${ }^{7}$ Frozen shoulders were associated in five of our patients with hemiplegia. Overall, 19 of the 100 patients had had a stroke affecting upper limb power.

\section{Discussion}

Our 100 cases are representative of patients currently admitted to acute and rehabilitation geriatric units. ${ }^{1617}$ Previous studies ${ }^{49} 910$ suggested that a high prevalence of peripheral joint disorders should be expected. Earlier work ${ }^{18}$ has been extended by relating recognised criteria defining peripheral arthritis to function. In our population current loss of mobility was due in $48 / 100$ patients to arthritis.

The peripheral inflammatory arthritis contributing to the hospital presentation of 32 patients had not been acknowledged by either the patient or the medical record in nine cases. A further 10 of the 48 patients with functional impairment had not reported any joint problem despite appropriate questioning. Perhaps most concern should be directed towards the first nine, in whom the full cause of decreased function was not determined by the medical staff concerned. A routine examination of shoulder, hip, and knee joints could have rectified this and would have taken only a short time.

Only six patients had arthritis or its complications as their primary cause of hospital admission, and three of these had other active contributory diseases. This is consistent with the concept of other processes increasingly affecting the management and outcome of rheumatological disorders in the elderly. ${ }^{6}$

Six of our 100 patients had a clinical shoulder disorder which was not mentioned on initial questioning, though three of these patients complained of shoulder pain when the range of movement of the joint was actively tested. This can be compared with the results of another survey, ${ }^{7}$ in which 18 acute geriatric patients without inflammatory arthropathy did not volunteer symptoms of shoulder disorder though 21 of the 100 studied did have such $\overrightarrow{\overrightarrow{\vec{t}}}$ disorder; our comparative figure is 15 out of 95 . A shoulder disorder is sufficiently common to require medical awareness. It is difficult to generalise further because selection criteria for the patients previously studied ${ }^{7}$ differed from ours, with variable sex ratio. The prevalence of stroke associ $s$ ated frozen shoulder was almost identical with the figure of $25 \%$ reported previously. ${ }^{19}$

The prevalence of the various arthritic diseases and the joints affected are consistent with pasto surveys. $^{91017}$ The most closely comparable survey, ${ }^{17}$ also of 100 consecutive acute geriatrico patients, reported 62 with abnormal knee joints and $w$ 16 with shoulders with pain and loss of movement $N$ which compares with our figures of 54 and 205 respectively. We did not examine in detail the wrise or elbow joints as disease in these joints, unless severe, causes less relative functional impairmento than arthritis of the hands, shoulders, hips, and knees. Because of the high incidence and prevalence of fractures of the proximal femur, particularly ino women, in the age groups examined the prevalence of hip arthritis is difficult to ascertain accurately Our figure of $21 \%$ is a minimum figure, to which can be added two patients who had had bilateral hipo replacements for probable OA.

A major problem in this survey and others is the lack of defined criteria for OA. Regrettably, the most recent and perhaps best criteria for idiopathic $\mathrm{OA}$ of the knee require pain in the joint as a prerequisite to the diagnosis. ${ }^{8}$ Yet severely de? ranged joints do not have to be painful, and many of our patients had disease processes that could de? crease joint pain. Pain is also relative, and again several of our patients had other diseases that produced much worse pain that that due to theip OA. For this reason other clinical criteria were used. ${ }^{910}$ The prevalence of symptomatic knee OA in our patients was similar to that in the study of Forman et $a l^{9}$ and to that in the studies at: Framingham $^{20}$ and Bath. ${ }^{17}$

We believe our criteria are more clinically valid than those based mainly on investigative screening 옥 particularly those using plain $x$ rays. The poorw correlation between clinical and radiological signs in? $\mathrm{OA}$ is well known. ${ }^{21}$ This can be extended to the relation between radiological chondrocalcinosis and pyrophosphate arthropathy-a relation which is not absolute. ${ }^{13} 17$ Pyrophosphate arthropathy was? assumed to be present in the two patients in whom clinical evidence of joint disease was associated with? radiological chondrocalcinosis. The radiological pre $\mathbb{Q}$ valence in a similar population has been measured, ${ }^{17}$ and this suggests that most patients with chondrocal 
cinosis were missed by us as they had no clinical joint disease.

Although the findings of our hospital survey can be related in general terms to two community based studies of the prevalence of arthritis in the elderly, ${ }^{10} 20$ any deductions must be guarded. The prevalences appear to be similar, however. This suggests that as many as $20 \%$ of the elderly in the community have arthritic joint disease that is affecting function but which is unrecognised by the patient as a specific problem. Community based studies are needed to evaluate this. Confirmation may direct the evolution of strategies to minimise disability and dependency in the elderly.

We are grateful to Dr Bakshi for allowing us access to his patients. Dr Scott receives support from the Arthritis and Rheumatism Council.

\section{References}

1 Stout R W, Crawford V. Active-life expectancy and terminal dependency: trends in long-term geriatric care over 33 years. Lancet 1988; i: 281-3.

2 Campbell A J, Bunyan D, Shelton E J, Caradoc-Davies T. Changes in levels of dependency and predictors of mortality in elderly people in institutional care in Dunedin. NZ Med J 1986; 99: 507-9.

3 Wilkins R, Adams B. Health expectancy in Canada, late 1970's: demographic, regional and social dimensions. American Journal of Public Health 1983; 73: 1073-80.

4 Abrams M. Three score years and ten. London: Age Concern, 1977.

5 Hunt A. Problems of the elderly. Vol 6. London: Age Concern, 1978: 7-8.

6 Gibson T, Grahame R. Rehabilitation of the elderly arthritic patient. Clin Rheum Dis 1981; 6: 485-95.
7 Chard M D, Hazleman B L. Shoulder disorder in the elderly (a hospital study). Ann Rheum Dis 1987; 46: 684-7.

8 Altman R, Asch E, Bloch D, et al. Development of criteria for the classification and reporting of osteoarthritis. Classification of osteoarthritis of the knee. Arthritis Rheum 1986; 29: 1039-49.

9 Forman M D, Malamet R, Kaplan D. A survey of osteoarthritis of the knee in the elderly. $J$ Rheumatol 1983; 10: 282-7.

10 Bergström G, Bjelle A, Sundh V, Svanborg A. Joint disorders at ages 70,75 and 79 years-a cross-sectional comparison. $\mathrm{Br} \mathrm{J}$ Rheumatol 1986; 25: 333-41.

11 Ropes M W, Bennett G A, Cobb S, Jacox R, Jessar R A. 1958 revision of diagnostic criteria for rheumatoid arthritis. Bull Rheum Dis 1958; 9: 175-6.

12 Cyriax J. Textbook of orthopaedic medicine. Vol 1. Diagnosis of soft tissue lesions. London: Ballière Tindall, 1971.

13 Doherty M, Dieppe P. Crystal deposition disease in the elderly. Clin Rheum Dis 1986; 12: 97-111.

$14 \mathrm{Katz}$ S, Akpom C A. A measure of primary sociobiological functions. Int J Health Serv 1976; 6: 493-507.

15 Hodkinson H M. Evaluation of a mental test score for assessment of mental impairment in the elderly. Age Ageing 1972; 1: 233-8.

16 Caradoc-Davis T $\mathrm{H}$. Medical profiles of patients admitted to a geriatric assessment and rehabilitation unit. $N Z \mathrm{Z} \mathrm{Med} \mathrm{J} \mathrm{1987;}$ 100: $557-9$.

17 Wilkins E, Dieppe P, Maddison P, Evison G. Osteoarthritis and articular chondrocalcinosis in the elderly. Ann Rheum Dis 1983; 42: $280-4$.

18 Gibson T. Disease of joints. In: Pathy M S J, ed. Principles and practice of geriatric medicine. Chichester: Wiley, 1985: 1059 103.

19 Jayson M I V. Frozen shoulder and adhesive capsulitis. Br Med $J$ 1981; 283: 1005-6.

20 Felson D T, Naimark A, Anderson J, Kazis L, Castelli W, Meenan R F. The prevalence of knee osteoarthritis in the elderly. The Framingham osteoarthritis study. Arthritis Rheum 1987; 30: 914-8.

21 Valkenburg H A. Clinical versus radiological osteoarthritis in the general population. In: Peyron J G, ed. Epidemiology of osteoarthritis. Paris: Ciba-Geigy, 1981: 53-8. 